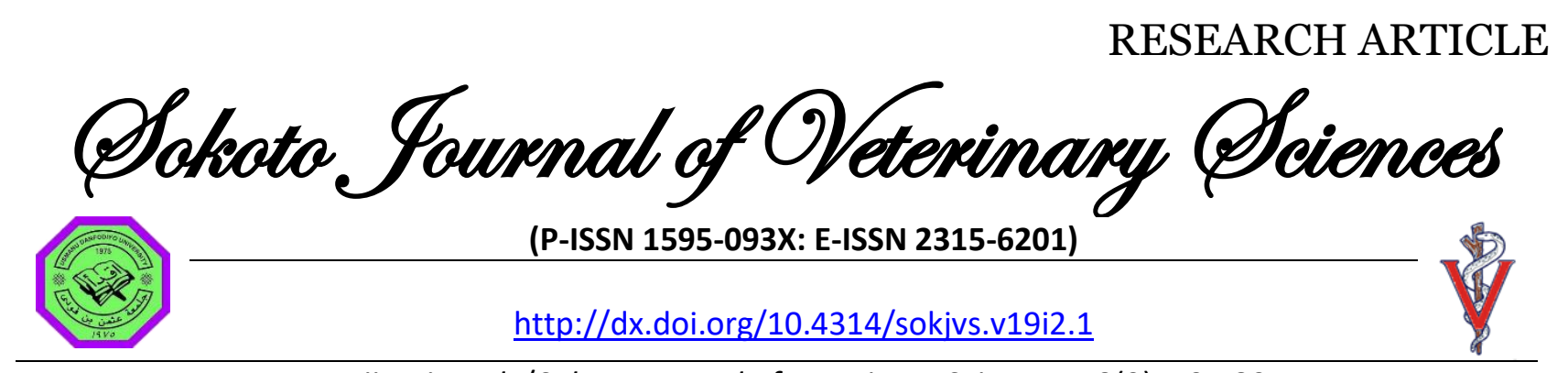

Fajinmi et al. /Sokoto Journal of Veterinary Sciences, 19(2): 73 - 80.

\title{
Haematological changes in Wistar rats experimentally infected with Trypanosoma congolense and Trypanosoma brucei brucei obtained from North-west Nigeria
}

\author{
AO Fajinmi ${ }^{1}$, OO Faleke ${ }^{2}$, AA Magaji ${ }^{2}$, UM Chafe $^{3}$, MA Kassim $^{1}$, UB Musa ${ }^{1}$, \\ MT Ormaga ${ }^{1}$, T Tese $^{1 *} \&$ M Hussaini $^{1}$ \\ 1. Nigerian Institute for Trypanosomiasis Research, Kaduna, Nigeria \\ 2. \\ Department of Veterinary Public Health and Preventive Medicine, Faculty of Veterinary Medicine, Usmanu \\ Danfodiyo University Sokoto, Nigeria \\ 3. Department of Veterinary Medicine, Faculty of Veterinary Medicine, Usmanu Danfodiyo University Sokoto, \\ Nigeria
}

*Correspondence: Tel.: +2347038355005; E-mail: timothytese@gmail.com

\begin{abstract}
Copyright: (c) 2021
Fajinmi et al. This is an open-access article published under the terms of the Creative Commons Attribution License which permits unrestricted use, distribution, and reproduction in any medium, provided the original author and source are credited.
\end{abstract}

Publication History: Received: 17-08-2020 Revised: 18-01-2021 Accepted: 19-01-2021

\section{Abstract}

This study determined haematological changes in Wistar rats experimentally infected with local strains of Trypanosoma congolense and Trypanosoma brucei brucei. Fortyfive Wistar rats between $10-12$ weeks old weighing between $210-240 \mathrm{~g}$ were used. The Wistar rats were randomly divided into four groups ( $A, B, C$ and $D)$, with the infected groups $(B, C$ and $D)$ having 10 rats each, while the uninfected control group (A) had 15 rats. Group A rats were not infected and served as the control, group B were infected with Trypanosoma congolense, group C were infected with Trypanosoma brucei brucei and group D were co-infected with Trypanosoma congolense and Trypanosoma brucei brucei. Infection was achieved using $0.1 \mathrm{~mL}$ of blood containing approximately $1 \times 10^{3}$ trypanosomes intraperitoneally into each Wistar rat in the infected groups. Clinical signs were observed. The changes in the blood cells were assayed in the groups post-infection. Duncan's Least Square Deviation showed significantly $(p<0.05)$ higher parasitaemia in infected groups. However, group $D$ showed a higher significant $(p<0.05)$ difference in parasitaemia when compared to groups $B$ and $C$. The pattern of mean parasitaemia for the infected groups, revealed a positive correlation with days of post-infection $(p<0.05)$ before the decline. The packed cell volume, total red blood cell count and haemoglobin concentration were significantly $(p<0.05)$ lower in infected groups $B, C$ and $D$. The total white blood cell count, platelet counts and differential leucocyte count were significantly $(p<0.05)$ lower in infected groups when compared to the uninfected group. These findings suggest that co-infection with Trypanosoma congolense and Trypanosoma brucei brucei obtained from Wurno and Ngaski in Sokoto and Kebbi States respectively produced a more damaging effect on haematological parameters.

Keywords: Experimental infection, Haematology, Wistar rats, Trypanosoma brucei brucei, Trypanosoma congolense 


\section{Introduction}

Trypanosomiasis is one of the most devastating diseases of man and animals in sub- Saharan Africa and has a profound effect on rural development (Silva et al., 1999). Trypanosomiasis occurs between latitudes $14^{\circ} \mathrm{N}$ and $29^{\circ} \mathrm{S}$, approximately one third $(1 / 3)$ of total land mass in tropical Africa, covering an area of 10 million $\mathrm{Km} 2$ (Nigerian Institute for Trypanosomiasis Research (NITR), Annual Report, 1989; Molyneux et al., 1996; Steverding, 2008; Sumayin et al., 2010). Animal trypanosomiasis constitutes a major threat to food security in Nigeria and other parts of sub-Sahara Africa (Onyiah, 1997; Swallow, 2000; Abenga et al., 2003; Fajinmi et al., 2006; Samdi et al., 2010). The disease is a major cause of livestock death in Africa each year leading to reduction in livestock populations, calving rates, milk yield, meat supply, work efficiency of draft animal and mixed farming (Swallow, 2000). African trypanosome species are hemoflagelate, extracellular and single cell protozoan parasites and the disease caused is associated with anemia, leucopenia, thrombocytopenia, plasma biochemical changes and lesions in some tissues and organs (Maikai \& Adaudi, 2007). Tsetse flies of the genus Glossina species are the principal vector of trypanosomes that are of major threat to livestock industry and include Trypanosoma vivax ( $T$. vivax), Trypanosoma congolense ( $T$. congolense) and Trypanosoma brucei brucei (T. b. brucei). Understanding the manifestations of trypanosome infection in the past has been largely based on single species experimental infection (Losos \& Ikede, 1970, 1972; Poltera, 1985; Anere et al., 2009) while there is dearth of investigation on experimental mixed trypanosome infections. Several of the natural occurrences of trypanosomiasis in animals arise from mixed infection (Nantulya, 1990). There is therefore likelihood that the true impact of the disease on the animal might have been under estimated. In West Africa including Nigeria, $T$. congolense and $T . b$. brucei are pathogenic to animals, though they are said to be of less threat to livestock compared to $T$. vivax (Jordan, 1986; Losos, 1986). Haematological parameter determination in relation to trypanosome infection is very important as it normally gives the true health status of the animals as well as indicator for anaemic conditions. In this work, attempt was made to investigate the haematological changes and compare the severity of $T$. congolense, $T$. b. brucei and co-infection on some haematological parameters in Wistar rats experimentally infected.

\section{Materials and Methods Wistar rats}

A total number of 45 Wistar rats of average weight between 210 - $240 \mathrm{~g}$ were used for this study. All the Wistar rats were bred at Nigerian Institute for Trypanosomiasis Research (NITR), Kaduna in commercial rat cages. The Wistar rats were also conditioned for a period of two weeks in the laboratory and certified parasite free by blood film microscopy prior to the infection. The Wistar rats were fed daily on vegetables supplemented with potatoes and water was made available ad libitum

\section{Experimental design}

The Wistar rats were randomly assigned into four groups with the infected groups having 10 rats each, while the uninfected control group had 15 rats. The groupings and their treatments were, uninfected Wistar rats / the control (Group A), Wistar rats infected with Trypanosoma congolense (Group B), Wistar rats infected with Trypanosoma brucei brucei (Group C) and Wistar rats infected with Trypanosoma congolense and Trypanosoma brucei brucei (group D).

This study was scrutinized and approved by the Nigerian Institute for Trypanosomiasis Research Committee on Medical and Scientific Research Ethics. General care of the rats was provided in accordance with the Institutional Animal Care and Use Committee, as outlined in the Guide for the Care and Use of Agricultural Animals in Research and Teaching.

\section{Parasite}

Trypanosome strains used were $T$. congolense (Sokoto/Wurno) and T. b. brucei (Kebbi/Ngaski). Both strains were isolated from cattle in Wurno Local Government Area Sokoto and Ngaski Local Government Area of Kebbi States respectively and cryo-preserved in liquid nitrogen at the Institute. The parasite strains were inoculated into donor uninfected Wistar rats intraperitoneally and maintained by repeated passaging. Parasitaemia was monitored by preparing a thin film of blood obtained from animal tail according to the method of (Woo, 1970).

Inoculation of Wistar rats with parasite

Blood from the infected donor Wistar rats (at peak parasitaemia) was collected and diluted with phosphate buffered saline (PBS). The number of parasites in the diluted blood was determined as 
described (Herbert \& Lumsden, 1976). Each rat in groups B, C and D was inoculated intraperitoneally with $0.1 \mathrm{ml}$ of blood containing approximately $1 \times 10^{3}$ trypanosomes as described (Abenga et al., 2017). Each rat in group A was inoculated intraperitoneally with $0.1 \mathrm{ml}$ of PBS (uninfected group) as placebo. Wistar rats in all the groups were observed daily for clinical signs, and for any changes in the body temperature and weights using a top-loading balance (ALISTONR AL730) and digital Precision Scale electronic balance (ATOMR-110C (Platinum) (Kelly, 1979) for 21 days post-infection (PI).

Daily rectal temperature $\left({ }^{\circ} \mathrm{C}\right)$ and packed cell volume (PCV) were taken every morning. The numbers of trypanosomes in the buffy coat were counted using the haematocrit centrifuge techniques (HCT) and a light microscope at $\times 40$ magnification (Woo, 1969 1970). Trypanosome species were identified by fixing thin blood smears in methyl alcohol and stained with $10 \%$ Giemsa solution (Woo, 1970). The slide was examined using $\times 100$ oil immersion objective.

\section{Haematology}

Blood obtained from the tail of infected rats was used for the daily estimation of parasitaemia as described (Herbert \& Lumsden, 1976) and packed cell volume (PCV) by micro haematocrit method (Cheesbrough, 2000) and Haemoglobin (Hb) concentration by (Jain, 1986). At 21 days PI, blood was collected from the heart of surviving rats using a sterile $2 \mathrm{ml}$ syringe and used immediately for determination of total red blood cell (RBC) and total white blood cell (TWBC) counts by the hemocytometer method as described by Dacie \& Lewis (1995), and platelets count as described by Kelly (1979). The blood smears were directly prepared and stained by Leishman's stain for differential white blood cell count (DWBC) by Battlement method (Houwen, 2001).

\section{Statistical analysis}

Data were analyzed using SPSS and Minitab packages. ANOVA and Duncan's multiple range tests were used to identify the cause of difference among the variables as described by Anere et al. (2009). The regression and correlation analyses were performed to determine the trend of the variables with $\mathrm{Pi}$ period. The coefficient of determining R2, was used as a measure of the degree of variance in the variables as explained by Cohen \& Cohen)1983).

\section{Results}

Clinical signs were observed between days 4 to 5 in groups B and C PI while group D developed clinical signs between days 2 to $3 \mathrm{PI}$. There was a significant difference $(p<0.05)$ in the mean temperature of the infected groups ( $B, C$ and $D$ ) compared to the control group (A). The Duncan's LSD revealed that group $D$ and $C$ recorded higher significant difference in temperature (Table 1). The temperatures of groups $B$ and $D$ increased at the same pace with increase in parasitaemia (group B, R2 $=83.59 \%$, group D, R2 = $83.50 \%, p<0.05)$ while the temperature of group $C$ had no significant increase with increase in temperature $(R 2=0.04 \%, p>0.05)$ (Figure 1$)$. All the Wistar rats in groups $B$ and $C$ started developing parasitaemia between days 5 to $6 \mathrm{PI}$, while group D developed parasitaemia between days 2 to $3 \mathrm{PI}$ (Figure 2).

Peak parasitaemia occurred between days 14 to 15 for group B; group $C$ had its peak between days 16 to 17 while group $D$ had its peak between days 10 to 11. The parasitaemia reduced from day 17 till death for group $C$, group $D$ from day 18 till death while group $B$ reduced from days 14 to 17 . Mortalities were recorded earlier in group $C$ than in groups $B$ and D. However, there was no significant difference between the parasitaemia of the infected groups, $(p>0.05)$ as presented in Table 1 . There was a significant difference $(p<0.05)$ in the mean PCV of the infected groups ( $B, C$ and $D)$ compared to the control group (A). The Duncan's LSD revealed that groups $D$ and $C$ recorded higher significant difference in PCV (Table 1). The PCV of the uninfected group (50.56 \pm 02.42) almost doubled those of infected groups $(36.88 \pm 8.75,39.37 \pm 7.65$ and $38.34 \pm 8.97$ ) respectively (Figure 3 ). Group B exhibited the lowest PCV value, which declined about $15 \%$ between day 0 to $21 \mathrm{PI}$ while other groups showed $8.9 \%$ and $5.9 \%$ respectively. Generally, there was significant change in mean PCV of the infected groups, $(p<0.05)$ compared to the control group. The initial parasitaemia and PCV correlated well from days 1 to 4, (Figure 4). At zero parasitaemia, the Wistar rats had normal PCV of $44.00 \pm 7.81$ to $54.26 \pm 4.32 \%$ while the PCV significantly reduced with increasing parasitaemia from day 7 till death. The R2 values of groups B, C and $D$ were $(87.0,87.1$ and $89.6 \%)$ respectively, showing significant $(p<0.05)$ trend with increase PI period of 21days.

There was a significant difference $(p<0.05)$ in $\mathrm{Hb}$ concentration and $\mathrm{MCV}$ of the infected groups (B, C and D) compared to the control group (A). The Duncan's LSD revealed that group $D$ and $C$ recorded higher significant difference in MCV (Table 1). The 


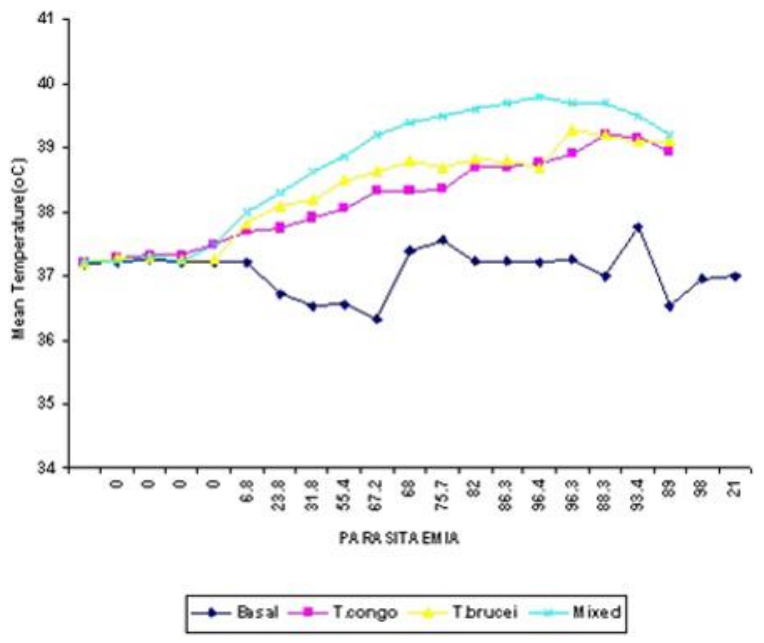

Figure 1: Relationship between mean temperature and parasitaemia of infected Wistar rats

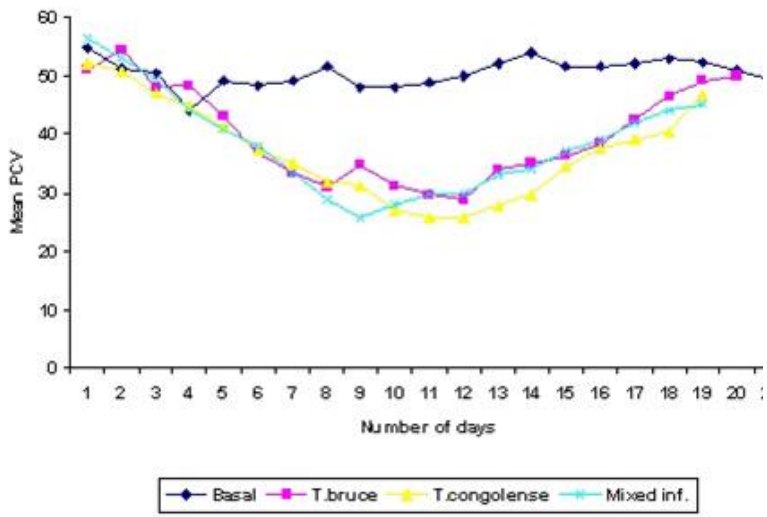

Figure 3: Relationship between PCV of control and infected Wistar rats

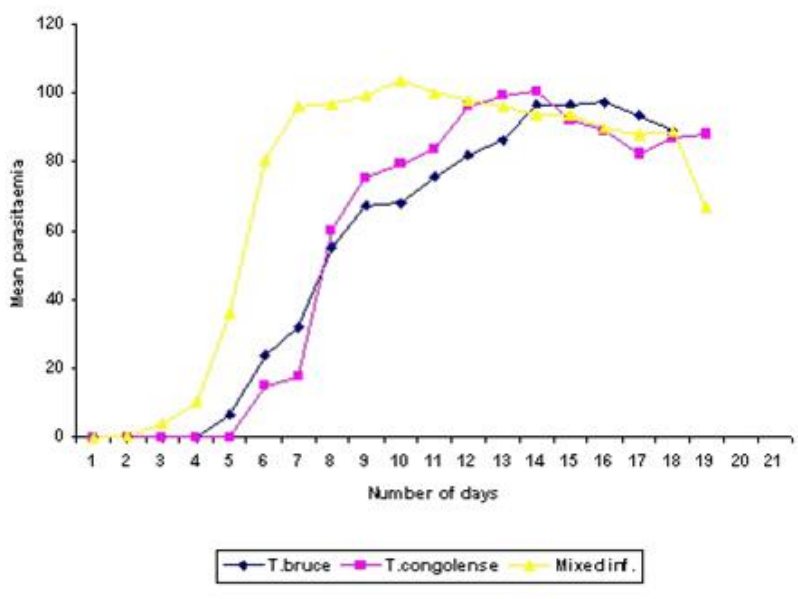

Figure 2: Mean parasitaemia of infected Wistar rats

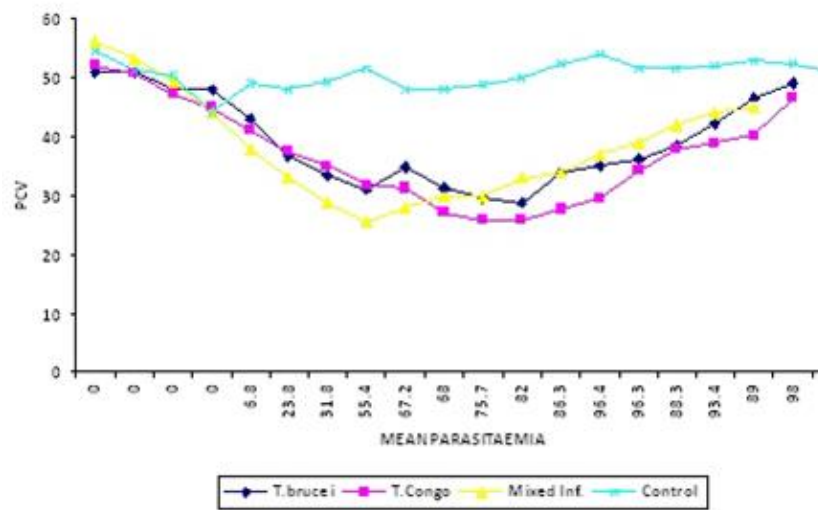

Figure 4: Relationship between parasitaemia ( $T . \quad b$. brucei) and PCV in Infected Wistar rats

Table 1: Average changes in weights, mean temperature, $\mathrm{PCV}, \mathrm{MCV}, \mathrm{Hb}$ and parasitaemia of the control and infected Wistar rats

\begin{tabular}{lllllll}
\hline Groups & W $(\mathrm{g})$ & Mean temperature $\left({ }^{\circ} \mathrm{C}\right)$ & $\begin{array}{l}\text { Mean PCV } \\
(\%)\end{array}$ & MCV (fl) & Hb (g/dl) & Mean Parasitaemia \\
\hline A & 240 & $37.18 \pm 0.36$ & $50.56 \pm 2.42$ & $47.25 \pm 0.64$ & $16.85 \pm 1.39$ & - \\
B & 230 & $38.10 \pm 0.76$ & $36.88 \pm 8.75$ & $35.12 \pm 0.28$ & $12.29 \pm 2.43$ & $76.12 \pm 27.32$ \\
C & 220 & $38.13 \pm 0.69$ & $39.37 \pm 7.65$ & $52.49 \pm 0.63$ & $13.12 \pm 1.01$ & $69.24 \pm 29.47$ \\
D & 210 & $38.71 \pm 1.00$ & $38.34 \pm 8.97$ & $52.52 \pm 0.71$ & $12.78 \pm 1.91$ & $74.62 \pm 35.71$ \\
\hline
\end{tabular}

W: Weight, PCV: Packed Cell Volume, MCV: Mean Corpuscular Volume, Hb: Haemoglobin Concentration

Table 2: Average changes in RBC, total WBC and platelet counts of control and trypanosome infected Wistar rats at 21 days post-infection

\begin{tabular}{lllll}
\hline Parameters & $\begin{array}{l}\text { Group A N } \\
=15\end{array}$ & Group B N = 10 & Group C N = 10 & Group D N = 10 \\
\hline RBC $(\times 106 / \mu \mathrm{L})$ & $10.7 \pm 2.0$ & $*(10.9 \pm 2.8) 10.5 \pm 3.8$ & $(9.8 \pm 3.8) 7.5 \pm 4.3$ & $(7.9 \pm 3.6) 7.3 \pm 4.5$ \\
WBC $(\times 103 / \mu \mathrm{L})$ & $16.8 \pm 5.6$ & $(16.5 \pm 5.3) 13.2 \pm 5.8$ & $(16.2 \pm 4.6) 12.1 \pm 5.3$ & $(14.91 \pm 5.5) 6.8 \pm 1.3$ \\
Platelet Counts & $461 \pm 0.2$ & $(481.5 \pm 3.3) 396.5 \pm 1.8$ & $(426.5 \pm 2.9) 279.2 \pm 5.3$ & $(412.3 \pm 3.6) 144.4 \pm 3.9$ \\
$(\times 103 / \mu \mathrm{L})$ & & & & \\
\hline
\end{tabular}

$*:$ In parenthesis are pre-infection values 
total WBC counts also declined most in group $D$ $(p<0.05)$ while the least was recorded in group $B$ (Table 2). A similar trend of decrease in the mean platelets counts was observed in group $D$ showing highest decrease in platelets counts at the end of 21 days PI (Table 2). The absolute differential WBC counts of the experimentally infected Wistar rats are presented in Table 3. The decrease in lymphocyte and neutrophil counts were also highest in group $D$ than groups B and C. There was higher marked increase in monocytes counts in group $D(p<0.05)$. Likewise, eosinophilia occurred only in group D. A total of six (6) Wistar rats died within the last week of the experiment in group $D$ while three (3) mortalities each were recorded in the other two groups ( $B$ and $C$ ). There was no significant difference in body weight in all the infected groups ( $B, C$ and $D)$ when compared to the control group.

\section{Discussion}

Anemia is a major clinical feature of African trypanosomiasis in man and animals (Anosa, 1988a; Ogunsanmi et al., 1994). It has been established that the measurement of anemia gives a reliable indication of the disease status and productive performance of trypanosome infected animals (Ekanem et al., 2005; Ekanem et al., 2006). Anemia, indicated by a significant drop in PCV, $\mathrm{Hb}$ and MCV of infected Wistar rats (Table 1 ) is in agreement with earlier reports (Anosa, 1988b; Igbokwe et al., 1994; Ekanem et al., 2008; Faremi \& Ekanem, 2011) in trypanosome infected animals. The low PCV observed in the infected groups may be as a result of acute hemolysis due to growing parasitaemia infection. Previous studies have shown that infection with trypanosomes resulted in increased susceptibility of red blood cell membrane to oxidative damage probably as a result of depletion of glutathione on the surface of the red blood cell (Igbokwe et al., 1994, 1996; Taiwo et al., 2003; Akanji et al., 2009). Severity of anemia usually reflects the intensity and duration of parasitaemia. A number of reports (Ogunsanmi \& Taiwo, 2001; Umar et al., 2007; Ekanem \& Yusuf, 2008; Saleh et al., 2009) have also ascribed acute anemia in trypanosomiasis to proliferating parasites. The lower counts of TWBC, lymphocytes and neutrophils observed in the infected groups may be attributed to the immunosuppressive actions of trypanosome infection (Abubakar et al., 2005; Ekanem \& Yusuf, 2008). Leucocytosis which may be due to lymphocytosis have been implicated in trypanosomiasis and these conditions are usually as a result of 'wax and wear' syndrome on the animal immune system caused by the ever-changing variable surface glycoprotein of the infecting trypanosomes (Abubakar et al., 2005). This study showed that infected Wistar rats developed anemia as characterize by significant reduction in PCV values especially between days 7 and $19 \mathrm{PI}$ when they had to die due to non-treatment. The co-infected group showed up early parasitaemia from day $2 \mathrm{PI}$, followed by $T$. $b$. brucei group.

The mean PCV of the infected groups did not differ significantly ( $p>0.05)$. However, the mean PCV of the infected groups were significantly different when compared with the control group $(p<0.05)$. The initial signs of parasitaemia were intermittent pyrexia, lethargy, isolation, reduced feed in-take and rough hair coat later followed by anorexia and recumbency. The relationship between the parasitaemia and PCV (Figure 4) was determined to identify the trend of PCV during the period of infection. From days 1 to $4 \mathrm{PI}$, the PCV was high when the parasitaemia did not yet occur. There was 81.7\% decrease in PCV from days 5 to $6 \mathrm{PI}$ with $60.8 \%$ increase in parasitaemia. Throughout the period of infection, there was a general significant decrease $(p<0.05)$ in PCV with increasing parasitaemia. As the parasitaemia progressively increased by $90.9 \%$ from days 7 to $8 \mathrm{PI}$, the PCV significantly reduced. These present findings agree with similar works in which a significant fall in PCV of goats infected with $T$. vivax was reported by (Anosa \& Isoun, 1977; Masake, 1980; Murray \& Dexter, 1988; Sekoni et al., 1990). The parasitaemia load of T. b. brucei $(69.24 \pm 29.47)$, T. congolense (76.12 \pm 27.32) and co-infected group (74.62 \pm 35.71) respectively are not significantly different on day 21 PI $(p>0.05)$. The degree of relationship between

Table 3: Average changes in absolute differential WBC ( $x 10^{3} / \mathrm{ul}$ of blood) of control and trypanosome infected Wistar rats at 21 days post-infection

\begin{tabular}{lllll}
\hline Parameters $(\times 103 / \mu \mathrm{L})$ & Group A N = 15 & \multicolumn{1}{c}{ Group B N = 10 } & Group C N = 10 & Group D N = 10 \\
\hline Neutrophils & $4.2 \pm 2.6$ & $*(421 \pm 2.7) 3.2 \pm 2.5$ & $(4.5 \pm 2.9) 3.0 \pm 3.5$ & $(2.8 \pm 2.0) 2.6 \pm 3.2$ \\
Lymphocytes & $13.2 \pm 3.1$ & $(13.2 \pm 4.3) 10.9 \pm 0.8$ & $(12.9 \pm 5.6) 7.8 \pm 1.3$ & $(13.3 \pm 4.8) 6.1 \pm 0.2$ \\
Monocytes & $0.4 \pm 4.1$ & $(0.2 \pm 3.5) 0.2 \pm 2.5$ & $(0.4 \pm 1.0) 0.4 \pm 0.9$ & $(0.34 \pm 4.6) 0.5 \pm 3.4$ \\
Eosinophils & $0.0 \pm 0.0$ & $(0.0 \pm 0.0) 0.0 \pm 0.0$ & $(0.0 \pm 0.0) 0.0 \pm 0.0$ & $(0.0 \pm 0.0) 0.6 \pm 0.5$ \\
\hline
\end{tabular}

$*$ : In parenthesis are pre-infection values 
mean parasitaemia and $T . b$. brucei infected group was $(\mathrm{R} 2=0.8707)$. This reveals a significant $87.1 \%$ rise in parasitaemia with increasing number of days of PI $(p<0.05)$ before the decline. Likewise, the pattern of $T$. congolense $(R 2=0.870)$ reveals a significant increase in mean parasitaemia with increase in number of days PI $(p<0.05)$ before decline. The co-infection with $T . b$. brucei and $T$. congolense showed much more significant increase in mean parasitaemia in relation to the single infections ( $R 2=0.896, p<0.05)$.

The temperature of the infected groups doubled that of control. However, the co-infection group exhibited higher wave of temperature and maintained their temperature within $39.54^{\circ} \mathrm{C}$ till death. All the infected groups developed persistent fever within range of $38.05-39.80^{\circ} \mathrm{C}$ till death. It was observed that the mean temperature of the four variables which are $(37.18 \pm 0.36,38.10 \pm 0.76,38.13$ \pm 0.69 and $38.71 \pm 1.00$ ), respectively, under consideration exhibited a significant increase from the day of post-infection $(p<0.05)$. This increase was generally observed from days 4 and 5 to $17 \mathrm{PI}$ when the temperature began to decline. The Duncan's LSD revealed that co-infection and $T$. $b$. brucei caused the high significant difference.

This study showed that Wistar rats experimentally infected with T. b. brucei, T. congolense and coinfection developed acute form of trypanosomiasis which is associated with high rectal temperature, decrease in body weight, anemia, low PCV and finally death. The severity of the disease was more in co-infection and $T$. b. brucei infected Wistar rats.

\section{Acknowledgment}

Our profound appreciation goes to $\mathrm{Mr}$ Ibrahim Ajiboso, Mr Abo Aser Stephen, Mr Kehinde David and Mr Jerome Anere for their technical assistance, computer and statistical analysis as well as the Director General of the Nigerian Institute for Trypanosomiasis Research, Kaduna, Nigeria, for granting access to the Institute's laboratories and facilities for this study.

\section{Conflicts of Interest}

The authors declare no conflict of interest.

\section{References}

Abenga JN, Adamu S, Useh NM, Nok AJ, Ibrahim NDG, Sackey AKB \& Esievo KAN (2017). Early-stage leukocytosis in Nigerian pigs experimentally infected with Trypanosoma brucei. International journal of Biological and Chemical Sciences, 11(2): 67-78.
Abenga JN, Enwezor FNC, Lawani FAG, Ezebuiro C, Sule J \& David KM (2003). Prevalence of trypanosomiasis in trade cattle slaughter at Kaduna, Nigeria. Nigerian Journal of Parasitology, doi.10.4314/njpar.v41i2.1 107-110.

Abubakar A, Iliyasu B, Yusuf AB, Igweh AC, Onyekwelu NA, Shamaki BA, Afolayan DO \& Ogbadoyi EO (2005). Anti-trypanosomal and haematological effects of selected Nigerian medicinal plants in Wistar rats. Biochemistry, 17(2): 95-99.

Akanji MA, Adeyemi AO, Oguntoye SO \& Sulyman F (2009). Psidium guajava extract reduces trypanosomosis associated lipid peroxidation and raises glutathione concentrations in infected animals. EXCLI J., doi.10.17877/DE290R-8903.

Anosa VO \& Isoun TT (1977). Experimental Trypanosoma vivax infection of sheep and goats, the relationship between the parasitemia, the growth rate and anaemia. Nigerian Journal of Veterinary Medicine, $\mathbf{3}$ : 101-108.

Anosa VO (1988a). Haematological and biochemical changes in human and animal trypanosomiasis. Partll. Revue d'elevage et de medecine veterinaire des pays tropicaux, 41(2): 151-164.

Anosa VO (1988b). Haematological and biochemical changes in human and animal trypanosomiasis. Part I. Revue d'elevage et de medecine veterinaire des pays tropicaux, 41(1): 65-78.

Anere JI, Fajinmi AO \& Lawani FAG (2006). An analysis of Human African Trypanosomiasis

(HAT) in Nigeria. Science World Journal, 1(1): 11-13.

Anere JI, Fajinmi AO \& Ahmed AB (2009). Experimental studies on the dispersions of trypanosomes in the blood of infected rats and the probability of tsetse picking up trypanosomes from the dispersions. Animal Production and Research Advances, 5(2): 88-93.

Cheesbrough M (2000). District laboratory practice in tropical countries. (part 2). Cambridge. Cambridge University Press. Pp 297-298.

Cohen J \& Cohen P (1983). Applied Multiple Regression/Correlation Analysis for the Behavioural Science. Second edition, Lawrence Erbaum Associates, Publishers, Hillside, NJ. 
Dacie JV \& Lewis SM (1995). Practical haematology eighth edition. London: Churchill Livingstone Pp 37-85.

Ekanem JT \& Yusuf K (2008). Some biochemical and haematological effects of black seed (Nigella sativa) oil on T. brucei-infected rats. African Journal of Biomedical Research, 7(2): 153-157.

Ekanem JT, Kolawole OM \& Abbah OC (2008). Trypanocidal potential of methanolic extract of Bridelia ferruginea benth bark in Rattus novergicus. African Journal of Biochemistry Research, 2(2): 45-50.

Ekanem JT, Majolagbe OR, Sulaiman FA \& Muhammad NO (2006). Effects of honey supplemented diet on the parasitaemia and some enzymes of Trypanosoma bruceiinfected rats. African Journal of Biotechnology, doi.org/10.5897/AJB06.289.

Ekanem JT, Sulyman FA \& Adeyemi OS (2005). Therapeutic properties and serum iron in $T$. brucei infected rats treated with amodiaquine and mofloquine. Biokemistri, 17(2): 115-121.

Faremi AY \& Ekanem JT (2011). Haematological parameters and enzyme studies in Trypanosoma brucei-infected rats reared on Nigella sativa oil-based diet. Asian Journal of Biochemistry, doi. 10.3923/ajb.2011.90.97.

Fajinmi, AO, Abenga JN, Lawani FAG, Ukah JCA, Ikemereh ECD \& Nwabuko PU (2006). An outbreak and observation of trypanosomiasis in Friesian cattle at SabonBirni, Kaduna State of Nigeria. African Journal of Clinical and Experimental Microbiology, 7(3): 28-34.

Herbert WJ \& Lumsden WHR (1976). Trypanosoma brucei: A rapid "matching" method for estimating the host's parasitemia. Experimental Parasitology, doi.10.1016/0014-4894(76)90110-7.

Houwen B (2001). The differential count. Laboratory Hematology, 7(2):89-100.

Igbokwe IO, Esievo KA, Saror DS \& Obagaiye OK (1994). Increased susceptibility of erythrocytes to in vitro peroxidation in acute Trypanosoma brucei infection in mice. Veterinary Parasitology, 55(4): 279-286.

Igbokwe IO, Umar IA, Omage JJ, Ibrahim NDG, Kadima KB, Obagaiye OK, Saror DI \& Esievo KAN (1996). Effect of acute Trypanosoma vivax infection on cattle erythrocyte glutathione and susceptibility to in vitro peroxidation. Veterinary Parasitology, doi.10.1016/0304-4017(95)00887-x.

Jain NC (1986). Schalm's Veterinary Haematology. fourth edition, Philadelphia, PA: Lea and Febinger. Pp 567-72.

Jordan AM (1986). Trypanosomiasis Control and African Rural Development. Longman, London.

Kelly WR (1979). Veterinary Clinical Diagnosis. Second edition, Bailliere Tindall, London. Pp 145

Losos G (1986). Infectious Tropical Diseases. Longman, England, pp: 219-232.

Losos EJ \& Ikede BO (1970). Pathology of experimental Trypanosomiasis in the albino rat, rabbit, goat, and sheep. A preliminary report. Canadian Journal of Comparative Medicine, 34(3): 209-212.

Losos EJ \& Ikede BO (1972). Review of pathology of disease in domestic and laboratory animals caused by $T$. congolense, T. vivax, T. brucei, $T$. b. rhodensiense and $T$. b. gambiense. Veterinary Pathology, 9(suppl):1-71.

Maikai V \& Adaudi AO (2007). Effect of aqueous extract of Ximenia americana on some haematological parameters of mice experimentally infected with Trypanosoma Congolense. Animal Production and Research Advances, 3(2): 99-103.

Masake RA (1980). The pathogenesis of infection with Trypanosoma vivax in goats and cattle. Veterinary Records, doi. 10.1136/vr.107.24.551.

Molyneux DH, Pentreath V \& Doua F (1996). African Trypanosomiasis in Man. In: Manson's Tropical Diseases, GC Cook, editor. Twentieth edition, WB Saunders Company Limited, London. Pp 1171-1196.

Murray M \& Dexter TM (1988). Anaemia in bovine African trypanosomiasis. A review. Acta Tropical, 45(4): 389-432.

Nantulya VM (1990). Trypanosomiasis in domestic animals; the problems of diagnosis. Research in Science Technology International and Epidemiology, 9(2): 357367.

NITR Annual Reports (1989). NITR's Report for External Review Meeting. NITR's HQ's, Kaduna, Nigeria.

Ogunsanmi AO \& Taiwo VO (2001). Pathobiochemical mechanisms involved in the control of the disease caused by Trypanosoma congolense in African grey duiker (Sylvicapra grimmia). Veterinary 
Parasitology, doi.10.1016/s03044017(00)00410-6.

Ogunsanmi AO, Akpavie SO \& Anosa VO (1994). Haematological changes in ewes experimentally infected with $T$. brucei. Revue d'elevage et de medecine veterinaire des pays tropicaux, 47(1): 53-57.

Onyiah JA (1997). African animal trypanosomiasis: An Overview of the current status in Nigeria. Tropical Veterinaria, 15(3-4): 111116.

Poltera AA (1985). Pathology of human African trypanosomiasis with reference to experimental African Trypanosomiasis. Britain Medical Bulletin, 41(2): 169-174.

Saleh MA, Bassam MA \& Sanousi SA (2009). Oxidative stress in blood of camels (Camelus dromedaries) naturally infected with Trypanosoma evansi. Veterinary Parasitology, doi.10.1016/j.vetpar.2009.03.035.

Samdi SM, Abenga JN, Attahir A, Wayo B, Hamra SM, Kabiru M, Jijitar A, Ogunwale R \& Ramatu AA (2010). Constraints in the control of African trypanosomiasis the prevailing factors in Kurmin Kaduna, Northern, Nigeria. (Review Article): International Journal of Animal and Veterinary Advances, 2(1): 31-36.

Sekoni VO, Saror DI, Njoku CO, Kumi-Diaka J \& Paluwa Gl (1990). Comparative haematological changes following Trypanosoma vivax and Trypanosoma congolense infections in Zebu bulls. Veterinary Parasitology, 35(1-): 11-19.

Silva RAMS, Ramirez L, Souza SS, Ortiz AG, Pereira SR \& Davila AMR (1999). An outbreak of Trypanosoma vivax infection in a dairy herd in the Pantanal, Brazil. Revue d'elevage et de medecine veterinaire des pays tropicaux, 52(1): 35-38.

Steverding D (2008). The history of African trypanosomiasis. Parasites and Vectors, doi.10.1186/1756-3305-1-3.

Sumayin MH, Muhammad KH, Jijitar AM, Usman AO, Fajinmi AO, Kalejaiye JO, Wayo B \& Musa D (2010). Autonomous control, climate and environmental changes effects on trypanosomiasis in sub-saharan Africa: A review. Animal Production and Research Advances, 6(1): 25-29.

Swallow BM (2000). Impacts of trypanosomiasis on African agriculture. Programme against African trypanosomiasis; Technical and Scientific Series 2, Food and Agriculture Organization of the United Nations, Rome.

Taiwo VO, Olaniyi MO \& Ogunsanmi AO. (2003). Comparative plasma biochemical changes and susceptibility of erythrocytes to in vitro peroxidation during experimental Trypanosome congolense and $T$. brucei infections in sheep. Israel Journal of Veterinary Medicine, 58(4): 435-443.

Umar IA, Ogenyi E, Okodaso D, Kimeng E, Stancheva GI, Omage JJ, Isah S \& Ibrahim MA (2007). Amelioration of anaemia and organ damage by combined intraperitoneal administration of vitamins A and C to Trypanosoma brucei brucei-infected rats. African Journal of Biotechnology, 6: 2083-2086.

Woo PTK (1969). The Haematocrit centrifuge for the detection of trypanosomes in blood. Canadian Journal of Zoology, doi.10.1139/z69-150.

Woo PTK (1970). The haematocrit centrifuge techniques for the diagnosis of African trypanosomiasis. Acta Tropical, 27(4): 384386. 